\title{
Evaluation of Escape Route Design in Public Multi-Storey Housing in Malaysia for Elderly Occupants
}

\author{
Nurul Liyana Hanapi ${ }^{1,2}$, Sabarinah Sh Ahmad1,2, Azli Abd Razak ${ }^{2,3}$ \\ Centre of Studies for Architecture, Faculty of Architecture, Planning \& Surveying, \\ Universiti Teknologi MARA, Puncak Alam Campus, Selangor, Malaysia \\ Tropical Building Performance Research Group, Faculty of Architecture, Planning \& Surveying, \\ Universiti Teknologi MARA, Selangor, Malaysia \\ Faculty of Mechanical Engineering, Universiti Teknologi MARA, Selangor, Malaysia \\ liyana513123@gmail.com, sabar643@salam.uitm.edu.my, azlirazak@salam.uitm.edu.my \\ Tel: +6014-6291506
}

\begin{abstract}
Public multi-storey residential buildings in Malaysia are dependent on the passive design approach to ensure maximum safety during an emergency. Elements of escape route design include corridors, exits and staircases. This paper evaluates the escape route distance and duration for the elderly to evacuate the building to safety using Pathfinder simulations. The results show that the staircase has a significant contribution towards providing fast evacuation. Meanwhile, varying the width of the exit doors and corridors had minimal impact on evacuation. On average, the elderlies took longer to evacuate due to their slow speed of movement and limited physical capability.
\end{abstract}

Keywords: Multi-Storey, Escape Route Design, Evacuation, Simulation

eISSN: 2398-4287 (C) 2020. The Authors. Published for AMER ABRA cE-Bs by e-International Publishing House, Ltd., UK. This is an open access article under the CC BYNC-ND license (http://creativecommons.org/licenses/by-nc-nd/4.0). Peer-review under responsibility of AMER (Association of Malaysian Environment-Behaviour Researchers), ABRA (Association of Behavioural Researchers on Asians) and cE-Bs (Centre for Environment-Behaviour Studies), Faculty of Architecture, Planning \& Surveying, Universiti Teknologi MARA, Malaysia.

DOI: https://doi.org/10.21834/ebpj.v5iSI2.2521.

\subsection{Introduction}

The design on public multi-storey housing in Malaysia is to meet the housing needs of those from the low-income group. The housing policy has been drafted based on the issues that came to light with the assurance that the planning does not deviate within the 30 years of Malaysian development (Nur \& Ku Hassan, 2015). The low-income housing initiative is viewed as successful, but many discontents have been heard primarily on the safety factor of the building (Hashim, Samikon, \& Nasir, 2012; Husin, Nawawi, Ismail, \& Khalil, 2012, 2015; Husin \& Nawawi, 2014; Karim, 2012; Ramli, Akasah, \& Masirin, 2014). Other issues that have arisen over the years besides safety factor are poor management and maintenance, which could also contribute to the poor performance of safety features in buildings (Aini, Abdullah, Zubedy, Ulyani, \& Najib, 2012; Hashim, Samikon, Ismail, \& Ismail, 2015; Sulaiman, Hasan, \& Jamaluddin, 2016).

Safety issues become a concern if it hampers the maximum performance of the building during an evacuation process. Issues that arise during an evacuation are poor building performance and increased occupancy, which in turn could lead to stagnation and prolonged evacuation process. In the past five years, many evacuation studies are focused on multi-storey housing. The devastating fire that engulfed the Shanghai Residential Tower in 2010 that killed and injured many residents may have sparked the interest of research into building evacuation safety since then, as these four that are published in 2012 (Haitao et al., 2012; Liu, Zhang, \& Zhu, 2012; Ma \& Guo, 2012; Xing \& Tang, 2012).

eISSN: 2398-4287 @ 2020. The Authors. Published for AMER ABRA cE-Bs by e-International Publishing House, Ltd., UK. This is an open access article under the CC BYNC-ND license (http://creativecommons.org/licenses/by-nc-nd/4.0/). Peer-review under responsibility of AMER (Association of Malaysian Environment-Behaviour Researchers), ABRA (Association of Behavioural Researchers on Asians) and cE-Bs (Centre for Environment-Behaviour Studies), Faculty of Architecture, Planning \& Surveying, Universiti Teknologi MARA, Malaysia.

DOI: https://doi.org/10.21834/ebpj.v5iSI2.2521. 
In 2014, a study based in Indonesia proposed a suitable fire protection system for residential areas (Sujatmiko, Dipojono, Soelami, \& Soegijanto, 2014). However, the fire protection system could not be applied to the public multi-storey residential area due to cost constraint. The latest research trend for multi-storey buildings proposed the lift as an alternative means of vertical transportation, but again, this approach did not suit the development of public housing due to the cost constraint (Chen, Wang, \& Fang, 2016; Zhang, 2017). The most relevant study area for multi-storey buildings that does not involve an active fire protection approach is the study in the staircase area. The study area can include a study on the flow rate, merging effect, and stack effect due to the smoke movement (Hu, You, Zhang, Wei, \& Guo, 2018; Kuligowski, Peacock, Wiess, \& Hoskins, 2013; Li et al., 2017; Shi et al., 2014; Wang, Ban, Liu, \& Zhao, 2013). It is the most common study as people rely on the staircase during a multi-storey evacuation. However, there is still minimal consideration given on the corridor and exit designs in the multi-storey evacuation. The study on the effect of fire and smoke is hard to perform since there is no prediction on the location of fire ignition and the level of fire and smoke spreading. Since this study emphasis on the effectiveness of building design layout, the fire propagation seems insignificant for this study.

As for the public housing in Malaysia, the evacuation process relies on the performance of passive design, which is the escape route design that will help to transport the building occupants to safety. However, building design performance for evacuation safety has not been thoroughly tested. Thus, this paper aims to evaluate the capability of escape route design in a typical public multi-storey building through a simulation study. The study scope is to keep the physical design of the housing intact for the next 30 years. Hence, the study did not make any changes to the overall planning of the building except for varying the width of the escape route pathways to find which element contributes to fast evacuation time.

\subsection{Method}

This paper is a part of a broader study on the emergency evacuation of a typical public multi-storey building in Malaysia. The study focuses on the movement of the evacuees, including the elderly residents during an emergency evacuation. The public multi-storey building is chosen due to the availability of the typical layout that becomes the guideline for the developer, where improving the existing design will give significant benefits for future developments. Figure 1 shows the three-dimensional (3D) view of the building used as a simulation model for the study where the building is shown as semi-transparent which allows better observation of the evacuees' movements in the building. The building model consists of 17 levels with 20 units of housing at every level, totalling 340 units in one building mode. The floor to floor height is $2700 \mathrm{~mm}$, which creates a total height of 43.2 meter vertically. Each unit is assigned to have either 4,5 , or 6 occupants per household, which has been randomly placed throughout the building. As a result, three values are chosen to represent lower occupancy (1478), medium occupancy (1700) and high occupancy (2100) as shown in Table 1.

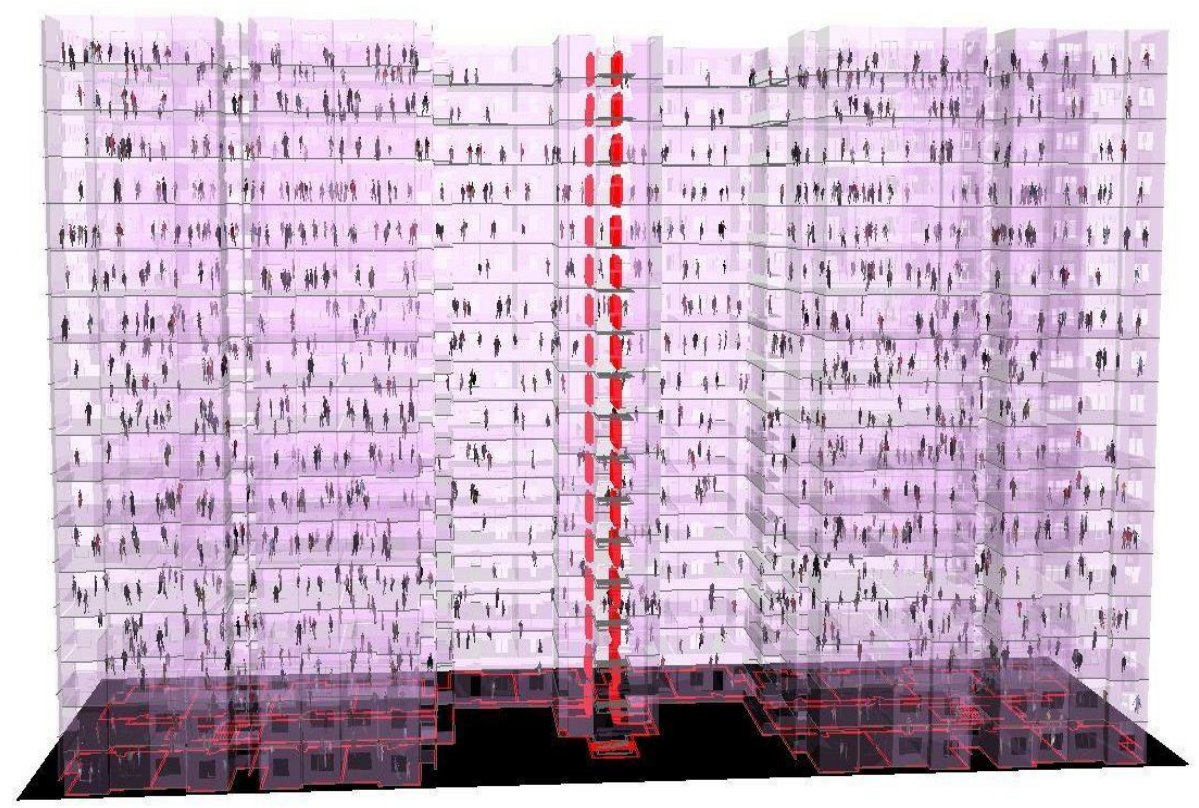

Fig.1: Three-dimensional view of the 17-storey building model used in the simulation study. 


\begin{tabular}{|c|c|c|c|c|c|c|c|}
\hline \multirow{2}{*}{ Scenario* } & \multirow{2}{*}{ Group } & \multicolumn{3}{|c|}{ Number of occupants } & \multicolumn{2}{|c|}{$\begin{array}{l}\text { Percentage } 0 \\
\text { occupants }\end{array}$} & \multirow{2}{*}{$\begin{array}{c}\text { elderly } \\
15 \%\end{array}$} \\
\hline & & 1478 & 1700 & 2100 & $7 \%$ & $10 \%$ & \\
\hline $\begin{array}{l}\mathrm{Ae} 1 \\
\mathrm{Ae} 2 \\
\mathrm{Ae} 3\end{array}$ & & $\mathrm{X}$ & $\mathrm{x}$ & $x$ & $\begin{array}{l}X \\
X \\
X\end{array}$ & & \\
\hline $\begin{array}{l}\mathrm{Be} 1 \\
\mathrm{Be} 2 \\
\mathrm{Be} 3\end{array}$ & Elderly & $x$ & $\mathrm{x}$ & $x$ & & $\begin{array}{l}X \\
X \\
X\end{array}$ & \\
\hline $\begin{array}{l}\mathrm{Ce} 1 \\
\mathrm{Ce} 2 \\
\mathrm{Ce} 3\end{array}$ & & $x$ & $x$ & $x$ & & & $\begin{array}{l}X \\
X \\
X\end{array}$ \\
\hline $\begin{array}{l}\text { Aa1 } \\
\text { Aa2 } \\
\text { Aa3 }\end{array}$ & & $x$ & $x$ & $x$ & $\begin{array}{l}X \\
X \\
X\end{array}$ & & \\
\hline $\begin{array}{l}\mathrm{Ba} 1 \\
\mathrm{Ba} 2 \\
\mathrm{Ba} 3\end{array}$ & Adults & $x$ & $x$ & $x$ & & $\begin{array}{l}X \\
X \\
X\end{array}$ & \\
\hline $\begin{array}{l}\mathrm{Ca} 1 \\
\mathrm{Ca} 2 \\
\mathrm{Ca} 3\end{array}$ & & $x$ & $x$ & $x$ & & & $\begin{array}{l}X \\
X \\
X\end{array}$ \\
\hline
\end{tabular}

This paper considers the movement of the elderly residents since the elderlies' walking speed is slightly different from the adult residents according to the speed that has been set by the IMO, where the speed range of elderly is between $0.56 \mathrm{~m} / \mathrm{s}$ to $1.62 \mathrm{~m} / \mathrm{s}$. In comparison, the range for the adults is $0.71 \mathrm{~m} / \mathrm{s}$ to $1.85 \mathrm{~m} / \mathrm{s}$. For this study, only elderlies with no physical ability were considered, and their behaviour is only affected by the surrounding factor (building design). No threat factor (fire and smoke) were considered in the study. The number of elderly residents is calculated based on the percentage of elderlies residing in the building, namely $7 \%, 10 \%$, and $15 \%$. Variations in the number of households and the elderly residents are made to study their effects on the evacuation process. Further details on the number of occupants and elderly residents are shown in Table 1.

Based on the variations to the number of occupants and elderly residents, 18 scenarios are designed to suit the study. All of the scenarios are given a coding where the upper-case letters indicate the percentage of elderly; where A represents $7 \%$, B represents $10 \%$, and $\mathrm{C}$ represents $15 \%$ of elderly residents. Meanwhile, the lower-case letters represent the elderly (e) and adult (a) occupants. As for the coding of the number, it indicates the total number of occupants from lower occupancy (1478), medium occupancy (1700) and high occupancy (2100).

The main objective of this study is to evaluate the escape route design for the public multi-storey building in Malaysia by varying the escape route width to determine which element contributes more towards fast evacuation. The three elements considered in the escape route design are staircases, corridors, and exits. Seven cases were designed to suit every element with different width for each element, namely $1300 \mathrm{~mm}, 1500 \mathrm{~mm}$, and $1800 \mathrm{~mm}$, as shown in Table 2.

Table 2: Cases with different scenarios in escape route design

\begin{tabular}{llll}
\hline No & Element of escape route & & Corridor \\
\hline Case 1 & Staircase & 1300 & 1300 \\
Case 2 & 1300 & 1300 & 1300 \\
Case 3 & 1500 & 1300 & 1300 \\
Case 4 & 1800 & 1500 & 1300 \\
Case 5 & 1300 & 1800 & 1300 \\
Case 6 & 1300 & 1300 & 1500 \\
Case 7 & 1300 & 1300 & 1800 \\
\hline
\end{tabular}

Pathfinder is the simulation tool selected to simulate the data as it has the flexibility to customise the layout, population and speed of the evacuees. The software predicts the evacuation duration of each occupant from the unit through the corridor and stairs to safety. The software allows for tracking and observation of the evacuee movement at every floor level. A total of 126 simulation tests were made based on the consideration of every scenario and case, as shown in Table 2. Case 1 is the base case or the control model with the original width of escape route design elements.

\subsection{Result and Discussion}


The simulation is run based on the input parameters stated in the previous section. The total and average evacuation duration by the elderly and the adult residents are tracked and recorded. The test is run multiple times to avoid the uncertainty of the evacuation time. Then the average value is calculated for each parameter analysed.

Figure 2 shows the total evacuation time needed for both the elderly and the adult occupants. Total evacuation time can be referred to as the duration taken between the raise of the alarm and the moment the last person is safely exiting the building. As overall, an increase of width in the staircase design (cases $2 \& 3$ ) has a significant contribution towards minimising the total evacuation time. The data are compared with the control model (case 1), which represents the typical layout of a public multi-storey residential building in Malaysia. For the corridor (cases $4 \& 5$ ) and exit (cases $6 \& 7$ ), both elements do not contribute much towards reducing the evacuation time when compared with the control model (case 1).

The colours in the graph (Figures 2 \&3) represent the different percentage of the elderly and adult occupants. In contrast, the different hues of colour represent the total number of occupancies from low to high. Blue, orange and grey represent the elderly occupant, where yellow, red and green represent the adult's occupant. Overall, the increased number of occupancies has a significant contribution to the total evacuation time, as increased occupancy results in increased total evacuation time. Figure 2 shows that the total evacuation time taken for both elderly and adult occupants are slightly similar if compared between low and occupancy. The total evacuation time needed for the elderly in low occupancy (blue) is similar to the total evacuation time needed for the adults in low occupancy (yellow). A similar result can be found in the medium (orange and red) and high (grey and green) occupancy. It is observed that the last person who exited the building, both the elderly and adult recorded similar evacuation time due to the location of exit that is near to the staircase area. The last elderly and adult occupants are queuing in the staircase area. The differences in speed between the elderly and the adult occupants are not evident due to the slow movement of the evacuees in the staircase area and did not have a significant contribution towards the evacuation time.

The different lines in Figure 2 represent the three-varying percentage of occupancies between the elderly and the adult. Based on the differences, an increase in elderly occupancy will increase the total evacuation time for the elderly. An increase in the elderly occupant will also affect the total evacuation time of the adult's occupants, due to the increasing number of those with a slow speed, affecting the overall evacuation process. However, the changes made by increasing the elderly occupancy are minimal.

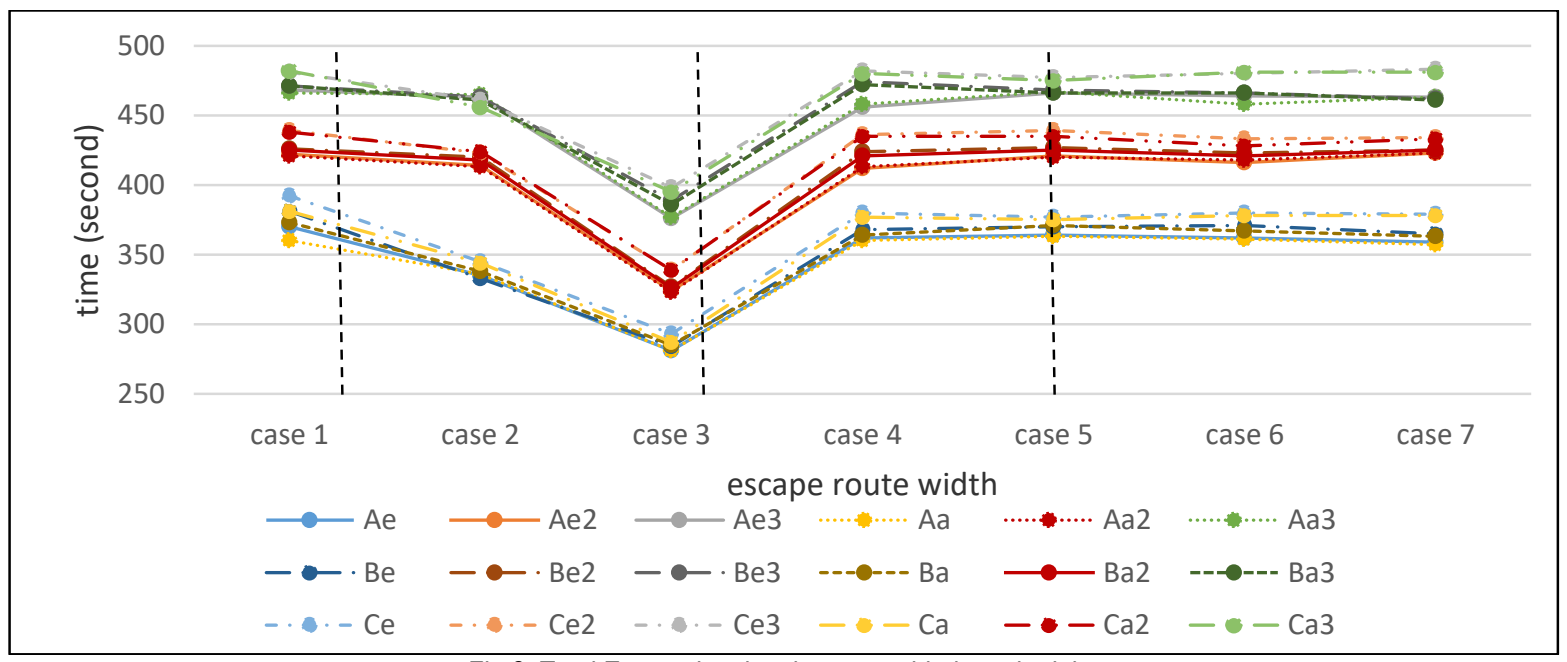

Fig.2: Total Evacuation time between elderly and adults

This paper only looks at the total evacuation time but also the average evacuation duration of the elderly and adults' occupants. The average is made based on the total summation of the evacuation time for every individual, subdivided by the number of occupancies during the evacuation time, as shown in Figure 3. The average time in Figure 3 shows a similar pattern as in Figure 2, where staircases (cases $2 \& 3$ ) have the most significant contribution towards minimising the evacuation time. As for the corridor (case $4 \& 5)$ and exit (case $6 \& 7$ ), not much difference is observed when compared with the control model (case 1).

Although the pattern of the graph for the average evacuation time is almost similar to the total evacuation time, the results show a different value of time between the elderly and adult occupants (compare between coloured lines) (Figure 3). Based on the coloured lines, the adult occupant could evacuate much faster when compared with the elderly occupant. Figure 3 shows that all the adults in low occupancy categories (yellow) evacuate much faster than the elderly in low occupancy categories (blue). The similar result also can be found in medium occupancy (compared between red and orange) and high occupancy (compared between grey and green). The results showed that the last person leaving the building was either the elderly or the adult as they evacuated using a similar duration. On average, the adult occupants have more potential in evacuation themselves much faster due to the physical ability and speed of the adult occupant is much higher than the elderly occupant. Overall, the finding from the average evacuation time is similar to the total evacuation time. An increase in the number of elderly and occupancy has a significant contribution to the evacuation time. 


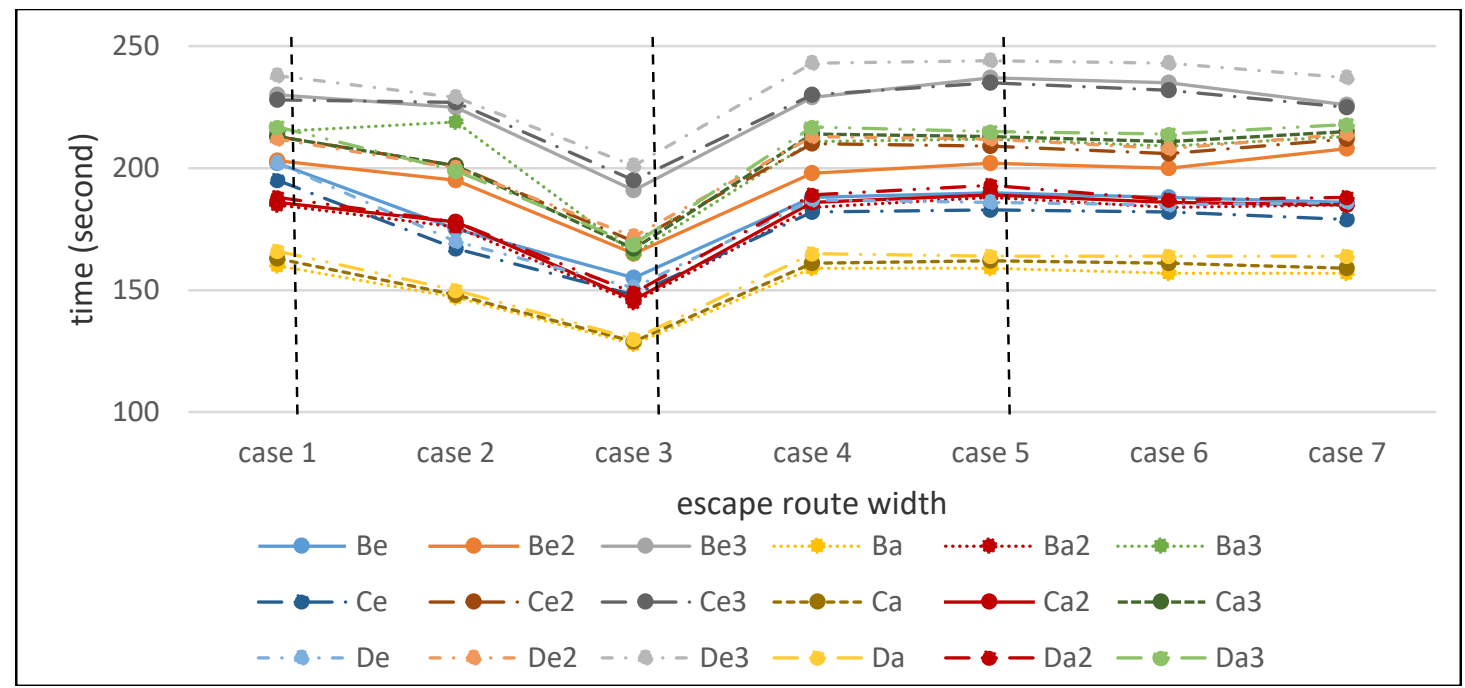

Fig.3: Comparison of average evacuation time between elderly and adults

Based on the data gathered from Figures 2 and 3, only the staircase design has a significant contribution to the evacuation time. An observation study is made through the simulation video in one of the scenarios tested to have a better understanding of why the staircase contributes to shorter evacuation duration. When the simulation is running, the movement of the evacuee is observed and tracked. Figure 4 shows the side view of the building during the evacuation process, where the majority of the evacuees are at the staircases, and only a few evacuees are using the corridor as they move to find an alternative escape route to transport them the fastest. The simulation predicts that the evacuees spend most of their time in the staircase area. Corridor and exit are used only during the initial evacuation process and when the evacuee seeks an alternative escape route. The observation can be used to support the finding on why the staircase contributes to significantly reducing the evacuation time when the width is increased. Staircases are the only means of vertical transportation that are available during the evacuation. The corridor and exit are the means to transport the evacuee horizontally. As for the multi-storey building, the only escape to safety is through the exit, which is only available at the ground level, thus creating a high dependency on the vertical transportation to transport the evacuees to safety. Wider staircase increases the flow rate and improves the staircase efficiency, which allows a reduction in the evacuation time.

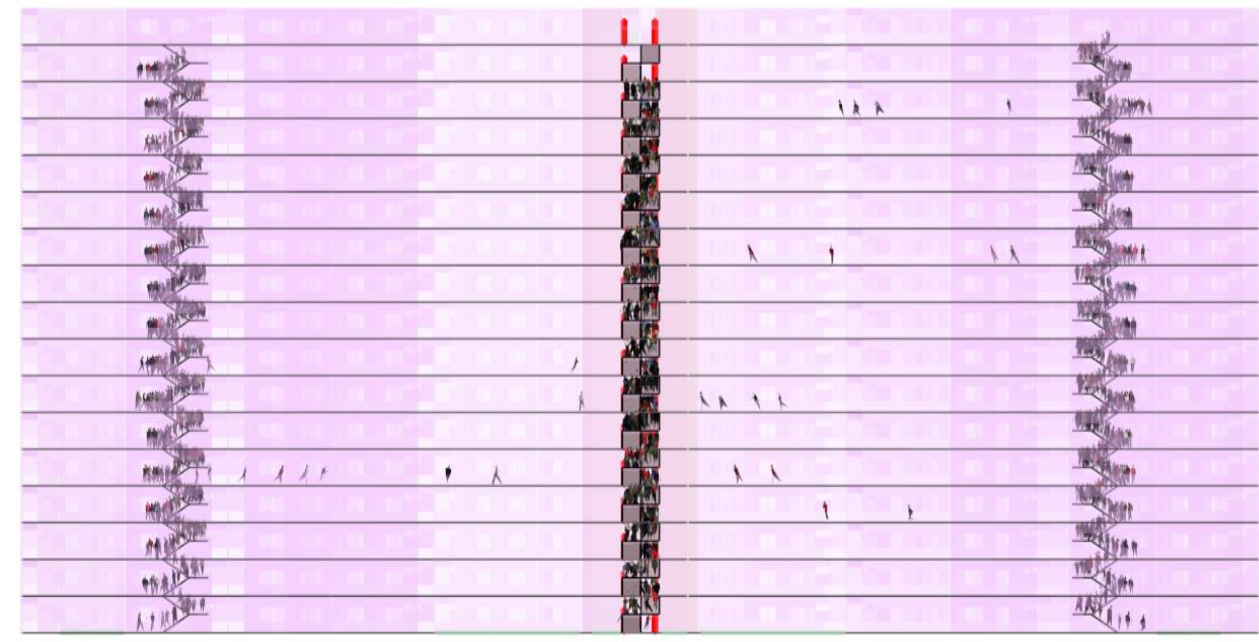

Fig.4: Side view of the 17-storey building during the evacuation process.

\subsection{Conclusion}

This paper studies the evacuation process of a typical public multi-storey housing in Malaysia. The main objective is to test the building layout design by varying the width of the staircases, corridors, and exits in escape route design to find how they affect the evacuation time. Of the three escape route design elements; the staircases have the most significant contribution towards reducing the evacuation time (case 2 and 3), as they are the main vertical transportation routes for the multi-storey building. Wider staircase proves to reduce the total evacuation time, which indicates that the staircase width has a positive correlation towards the evacuation time.

As for the corridor and exit, the contribution is minimal. Although the contribution is minimal towards reducing evacuation time, the elements are equally important, as they help to transport the evacuees horizontally. The contribution will become more significant for more complex building layout, which depends more on the horizontal evacuation towards the staircase. As for the number of elderly and 
occupancy, the increase of both factors will prolong the evacuation time and affect all the occupants involved during the evacuation process. Hence, high-density occupancy will prolong evacuation time and increase the occurrence of stagnation at the exit and staircase area.

This paper only considers the changes made by one element at a time; future studies could include various changes made to the escape route element to find the best design that helps to reduce the evacuation time. Only elderly and adult occupants have been considered in the study due to the consideration of different walking speeds. A future study could consider the differences between the physical abilities of occupants.

\section{Acknowledgement}

This paper is made possible through the studies conducted using the BESTARI GRANT (Project Number: 600-IRMI/MyRA 5/3/BESTARI (040/2017) awarded by the Institute of Research Management \& Innovation (IRMI), UiTM and a scholarship under MyBrain15 provided by the Ministry of Higher Education. The authors are also thankful to Thunderhead Engineering for providing free Pathfinder Software that was used in this study

\section{References}

Aini, N., Abdullah, S., Zubedy, S., Ulyani, N., \& Najib, M. (2012). Residents ' maintenance priorities preference : the case of public housing in Malaysia, 62(2003), 508513. https://doi.org/10.1016/j.sbspro.2012.09.083

Chen, J., Wang, X., \& Fang, Z. (2016). Collaborative Evacuation Strategy of Ultra-tall Towers among Stairs and Elevators. Procedia Engineering, 135, 170-174. https://doi.org/10.1016/j.proeng.2016.01.102

Haitao, C., Leilei, L., Jiuzi, Q., Chen, H., Lou, L., \& Qiu, J. (2012). Accident cause analysis and evacuation countermeasures on the high-rise building fires. Procedia Engineering, 43, 23-27. https://doi.org/10.1016/j.proeng.2012.08.005

Hashim, A. E., Samikon, S. A., Ismail, F., \& Ismail, Z. (2015). Managing Facilities on Malaysian Low-cost Public Residential for Sustainable Adaptation. Procedia - Social and Behavioral Sciences, 168, 52-60. https://doi.org/10.1016/j.sbspro.2014.10.209

Hashim, A. E., Samikon, S. A., \& Nasir, N. M. (2012). Assessing factors influencing Performance of Malaysian Low- Cost Public Housing in Sustainable Environment, 50(July), 920-927. https://doi.org/10.1016/j.sbspro.2012.08.093

Hu, J., You, L., Zhang, H., Wei, J., \& Guo, Y. (2018). Study on queueing behavior in pedestrian evacuation by extended cellular automata model. Physica A, 489, 112127. https://doi.org/10.1016/j.physa.2017.07.004

Husin, H. N., Nawawi, A. H., Ismail, F., \& Khalil, N. (2012). Preliminary Survey of Integrated Safety Elements into Post Occupancy Evaluation for Malaysia's Low Cost Housing. Procedia - Social and Behavioral Sciences, 36, 583-590. https://doi.org/10.1016/j.sbspro.2012.03.064

Husin, H. N., Nawawi, A. H., Ismail, F., \& Khalil, N. (2015). Correlation Analysis of Occupants' Satisfaction and Safety Performance Level in Low Cost Housing. Procedia - Social and Behavioral Sciences, 168, 238-248. https://doi.org/10.1016/j.sbspro.2014.10.229

Husin, H., \& Nawawi, A. (2014). Analysis on Occupants' Satisfaction for Safety Performance Assessment in Low Cost Housing. E3S Web of ..., 4. Retrieved from http://www.e3s-conferences.org/articles/e3sconf/abs/2014/02/e3sconf_etsdc2014_01004/e3sconf_etsdc2014_01004.html

Karim, H. A. (2012). Low Cost Housing Environment: Compromising Quality of Life? Procedia - Social and Behavioral Sciences, 35, 44-53. https://doi.org/10.1016/j.sbspro.2012.02.061

Kuligowski, E., Peacock, R., Wiess, E., \& Hoskins, B. (2013). Stair evacuation of older adults and people with mobility impairments. Fire Safety Journal, 62, $230-237$. https://doi.org/10.1016/j.firesaf.2013.09.027

Li, W., Li, Y., Yu, P., Gong, J., Shen, S., Huang, L., \& Liang, J. (2017). Modeling, simulation and analysis of the evacuation process on stairs in a multi-floor classroom building of a primary school. Physica A: Statistical Mechanics and Its Applications, 469, 157-172. https://doi.org/10.1016/j.physa.2016.11.047

Liu, X., Zhang, H., \& Zhu, Q. (2012). Factor analysis of high-rise building fires reasons and fire protection measures. Procedia Engineering, 45, 643-648. https://doi.org/10.1016/j.proeng.2012.08.216

Ma, Q., \& Guo, W. (2012). Discussion on the fire safety design of a high-rise building. Procedia Engineering, 45(3), 685-689. https://doi.org/10.1016/j.proeng.2012.08.223 Nur, W., \& Ku Hassan, K. A. (2015). Houses design of Low cost Housing in Malaysia. The Asia APcific Network for Housing Research, (April), 1-8.

Ramli, A., Akasah, Z. A., \& Masirin, M. I. M. (2014). Safety and Health Factors Influencing Performance of Malaysian Low-cost Housing: Structural Equation Modeling (SEM) Approach. Procedia - Social and Behavioral Sciences, 129, 475-482. https://doi.org/10.1016/j.sbspro.2014.03.703

Shi, W. X., Ji, J., Sun, J. H., Lo, S. M., Li, L. J., \& Yuan, X. Y. (2014). Influence of fire power and window position on smoke movement mechanisms and temperature distribution in an emergency staircase. Energy and Buildings, 79(Icbee 2013), 132-142. https://doi.org/10.1016/j.enbuild.2014.02.083

Sujatmiko, W., Dipojono, H. K., Soelami, F. X. N., \& Soegijanto. (2014). Performance-based Fire Safety Evacuation in High-rise Building Flats in Indonesia - A Case Study in Bandung. Procedia Environmental Sciences, 20, 116-125. https://doi.org/10.1016/j.proenv.2014.03.016

Sulaiman, F. C., Hasan, R., \& Jamaluddin, E. R. (2016). Users Perception of Public Low Income Housing Management in Kuala Lumpur. Procedia - Social and Behavioral Sciences, 234, 326-335. https://doi.org/10.1016/j.sbspro.2016.10.249 
Wang, P., Ban, Q., Liu, J., \& Zhao, C. (2013). Impacts of Staircase Windows on Pressurized Ventilation System. Procedia Engineering, 52, 363-370. https://doi.org/10.1016/j.proeng.2013.02.154

Xing, Z., \& Tang, Y. (2012). Simulation of Fire and Evacuation in High-Rise Building. Procedia Engineering, 45, 705-709. https://doi.org/10.1016/j.proeng.2012.08.227 Zhang, X. (2017). Study on rapid evacuation in high-rise buildings. Engineering Science and Technology, an International Journal. https://doi.org/10.1016/j.jestch.2017.04.007 